\title{
A PESQUISA E O DIREITO COMPARADO: UM PANORAMA EVOLUTIVO E OS DESAFIOS ENFRENTADOS NO BRASIL
}

\author{
Eduardo Gomes Ribeiro Maia ${ }^{1}$ \\ Jussara Maria Moreno Jacintho ${ }^{2}$
}

RESUMO: O artigo objetiva estudar os desafios enfrentados no Brasil relativos à pesquisa em direito comparado, fazendo, assim, uma análise evolutiva. Os indícios da comparação remontam à antiguidade, entretanto, sua origem oficial se deu apenas no século XIX. No século XX, tais estudos desenvolveram-se de fato, dando ensejo à divergência que perdura até hoje, que é o fato deste ser uma ciência ou um método. Contudo, apesar da discrepância entre autores, precisa-se ter a noção de que tal estudo é muito importante, pois contribui para o conhecimento do ordenamento jurídico nacional.

PALAVRAS-CHAVE: Direito comparado; método; evolução; desafios; ensino.

\section{THE RESEARCH AND COMPARATIVE LAW: AN EVOLUTIVE PANORAMA AND THE CHALLENGES FACED IN BRAZIL}

\begin{abstract}
The article aims to study the challenges faced in Brazil related to comparative law research, thus making an evolutionary analysis. The indications of the comparison go back to the antiquity, however, its official origin occurred only in Century XIX. In the twentieth century, such studies developed in fact, giving rise to the divergence that remains until today, which is the fact of this being a science or a method. However, despite the discrepancy between authors, it is necessary to have the notion that such a study is very important, since it contributes to the knowledge of the national legal order.
\end{abstract}

KEYWORDS: Comparative law; method; evolution; challenges; teaching.

\section{INTRODUÇÃO}

O presente artigo tem por objetivo analisar os desafios da pesquisa no direito comparado no Brasil, trazendo um panorama evolutivo, bem como as discussões acerca da sua natureza, além dos desafios enfrentados no Brasil, que decorreram das dificuldades encontradas em seu desenvolvimento.

\footnotetext{
${ }^{1}$ Mestrando em Direito pela Universidade Federal de Sergipe (UFS). Advogado. eduardomadv@ hotmail.com

${ }^{2}$ Doutora em Direito Constitucional pela PUC/SP. Mestre em Direito pela Universidade do Estado do Rio de Janeiro (UERJ/RJ). Professora da Universidade Federal de Sergipe (UFS). j.jacintho@uol.com.br
} 
Dessa forma, o tema proposto justifica-se com base na importância da pesquisa no âmbito do direito comparado, haja vista possibilitar meios de progresso e de profilaxia social, porquanto tal estudo permita reduzir os riscos da atividade legislativa, ao ampliar a visão do legislador, através do conhecimento das soluções práticas aplicadas em outros países para problemas comuns, por exemplo.

Na realização da pesquisa utilizou-se, especialmente, a análise de documentos, livros e artigos científicos, a partir de consulta diretamente nos livros e sites especializados.

O desenvolvimento foi dividido em três tópicos, os quais foram escritos de forma dissertativa. O primeiro cuida da evolução do direito comparado, fazendo uma análise desde os primeiros indícios do seu surgimento até a contemporaneidade.

O segundo tópico discorre sobre a natureza do direito comparado, abordando a divergência existente sobre este ser uma ciência ou método, explicando se a discussão ainda persiste e qual o sentido desta.

Por fim, no terceiro tópico foi tratado a respeito dos desafios enfrentados na pesquisa em direito comparado no Brasil, bem como soluções que podem ser adotadas para a ampliação da pesquisa nesse âmbito.

\section{EVOLUÇÃO HISTÓRICA}

Inicialmente, faz-se necessário realizarmos um panorama acerca da evolução histórica do direito comparado e, para tanto, serão analisados os aspectos relevantes no que diz respeito às obras, autores e eventos que levaram ao desenvolvimento deste, bom como sobre sua origem, natureza e, finalmente, os desafios enfrentados no estudo comparado.

Leontin-Jean Constantinesco, na obra Tratado de direito comparado: introdução ao direito comparado (1998, p. 69), explica que o direito comparado desenvolveu-se, de fato, ao longo do século XX, passando por uma lenta evolução e constantes modificações, principalmente, no século XIX.

Entretanto, pode-se dizer que, desde os tempos mais remotos, já existia um interesse relativo a este estudo, decorrente do direito estrangeiro e de um olhar dos estudiosos além do próprio direito, com iniciativas pessoais e esporádicas dos autores, de forma que tais experiências, apesar de não pertencerem ao direito comparado propriamente dito, foram responsáveis pelo progressivo desenvolvimento deste. 
Dessa forma, tem-se que já existiam indícios de comparação na antiguidade romana e grega e na Idade Média, embora não houvesse um método ou rigor para tal estudo. Segundo Leme (1960, p. 59), o interesse pelo direito estrangeiro "remonta à antiguidade. Assinala-o Mario Sarfatti, apresentando como exemplo a colheita de materiais constante da Lex Dei ou Collatio legum Romanarum et Mosaicarum, que surgiu no ano 400 da Era Cristã".

René David (2002, p. 25), na obra intitulada Os Grandes Sistemas do Direito Contemporâneo, conclui que:

\begin{abstract}
A comparação dos direitos, considerados na sua diversidade geográfica, é tão antiga como a própria ciência do direito. O estudo de 158 constituições que regeram cidades gregas ou bárbaras serviu de base ao Tratado que Aristóteles escreveu sobre a Política; Sólon, diz-se, procedeu do mesmo modo para estabelecer as leis de Atenas, e os decênviros na conceberam, segundo a lenda, a lei das XII Tábuas senão depois dum inquérito por eles levado a cabo nas cidades da Grande Grécia. Na Idade Média comparou-se direito romano e direito canônico, e o mesmo aconteceu em Inglaterra onde se discutiu, no século XVI, sobre os méritos comparados do direito canônico e da common law.
\end{abstract}

Sobre o assunto, Caio Mário Pereira (1955, p. 36) leciona:

O primeiro monumento comparatista é um trabalho anônimo realizado no IV século, e divulgado no Baixo Império com o título "Collatio Legum Romanarum et Mosaicarum", em que se confrontou o Direito Romano e o Direito Hebreu, com todas as falhas de uma experiência, mas com o mérito de significar um tipo de estudo de cunho comparatista inequívoco. Não teve maior desenvolvimento, porém, o método, pois somente veiu a despertar a atenção dos escritores na idade moderna, com os trabalhos de juristas inglêsses por volta do XV e XVI século. Em razão do direito inglês ter seguido uma linha de evolução indepedente dos países continentais, aparecem na Inglaterra obras como a de FORTESCUE no século XV. De Laudibus Legum Angliae, em que o autor tece os louvores do direito inglês em comparação com o direito francês, ou a de FULBECK, sob a forma de diálogo entre um jurista inglês, um canonista e um romanista, intitulada "The parallele or Conference of the Civil Law, the Canon Law and the Common Law of this Realm of England" ou a de ST. GERMAIN, Doctor and Student, igualmente sob forma de discussão entre um romanista e um jurista inglês.

Nesse toar, há registros de uma comparação sistemática entre os direitos costumeiros aplicados no interior de países como a França e Alemanha (CONSTANTINESCO, 1998, p. 70-71).

Destarte, até o final do século XVII, foram os ingleses os primeiros a realizarem comparações com os direitos estrangeiros. Na França, pode-se considerar que o grande precursor da comparação foi Montesquieu, com a obra O Espírito das Leis, que, conforme Constantinesco (1998, p. 80), "reconhecido como um dos fundadores da ciência política, 
Montesquieu realiza com o seu Esprit des lois uma verdadeira revolução intelectual, modificando profundamente a abordagem do problema".

Nesse ínterim, mais uma vez Constantinesco (1998, p. 72), assinala que a evolução do direito comparado se deu em três períodos; sendo o primeiro do ano de 1800 a 1850 , o segundo de 1850 a 1900, e o terceiro de 1900 a 1950; divisão que será adotada no presente artigo e analisada a seguir.

\subsection{PRIMEIRO PERÍODO (1800 - 1850)}

É no começo do século XIX que o Direito comparado tem suas origens oficiais, quando aparece com as nuances de método e/ou disciplina autônoma. Segundo Jescheck, “o direito comparado, no sentido de um método geral, sistemático e decisivo em razão do emprego de meios técnicos valiosos, começou a se mover somente no século XIX” (2006, p. 20, apud KHALED JR., 2010, p. 2).

Dessa forma, nesse período há um maior interesse dos juristas nacionais acerca dos direitos estrangeiros, de forma que há uma confusão entre estes e o direito comparado. Contudo, apesar da confusão, desperta-se a consciência de uma possível contribuição para o aperfeiçoamento do direito nacional, além da ampliação dos conhecimentos jurídicos, principalmente na França e na Alemanha. "Compara-se para compreender melhor, mas sobretudo para tirar proveito das experiências de outros povos" (CONSTANTINESCO, 1998, p. 94-96).

Outros precursores do direito comparado foram Grotius, Leibniz, Vico e Feuerbach, chamando atenção para o direito estrangeiro e preparando o caminho para a formação do direito comparado (CONSTANTINESCO, 1998, p. 84-103).

Deve-se destacar que foi Feuerbach quem lançou de fato os fundamentos da ciência do direito comparado, sendo um dos teóricos a aplicar a comparação aos direitos contemporâneos com a finalidade de política legislativa.

Dentre os autores dessa época destacam-se Zacharie que, influenciado por Kant, entende que "o conhecimento dos direitos estrangeiros deve permitir individualizar os princípios jurídicos comuns através da análise do desenvolvimento histórico das instituições”; e Mittermaier, sendo este o primeiro a orientar o direito comparado para as necessidades práticas, fazendo de seus estudos acerca dos direitos estrangeiros instrumentos empíricos 
destinados resolver problemas atuais, abrindo, assim, novos horizontes (CONSTANTINESCO, 1998, p. 117-125).

Por fim, Constantinesco (1998, p. 130) afirma que, durante esse período, o direito comparado passa a se difundir entre diversos juristas, embora o progresso seja ainda modesto, tendo em vista que não aprofunda no conhecimento dos direitos estrangeiros, ainda não é uma ciência autônoma, mas usado tão somente com a finalidade de uma aplicação prática no sistema nacional.

$\mathrm{O}$ autor menciona ainda que, ao final deste período, os progressos começam a se desvanecer, de forma que "os primeiros progressos necessários ao nascimento do Direito comparado se interrompem novamente de forma brusca. Somente no segundo período ele tomará, paulatinamente, um novo impulso" (CONSTANTINESCO, 1998, p. 132).

\subsection{Segundo Período (1850 - 1900)}

Nesse período, há a justaposição entre os ordenamentos. Outrossim, surgem diversas concepções acerca do direito comparado, de forma que este se desenvolve de forma distinta em cada país, conforme menciona Constantinesco (1998, p. 134):

Em alguns Estados, o Direito comparado é objeto de iniciativas individuais e teóricas que se manifestam em obras e monografias; em outros, é promovido por uma ação de grupo, com a ajuda das sociedades de legislação comparada e das vistas que perseguem, sobretudo, escopos práticos. Nos outros países, principalmente da Europa Ocidental e da América do Sul, o interesse pelos Direitos estrangeiros e, em menor medida, pela comparação deriva da difusão dos códigos - especialmente daqueles franceses - no mundo.

Esse período também é marcado pelo início da divergência acerca da definição do direito comparado, se este é uma nova disciplina ou um método. Entretanto, a comparação é tida de forma estreita e inexata. "Somente no final do segundo período compreende-se que o Direito não coincide com o simples texto de lei e que, para compreender o Direito estrangeiro, é preciso ir além da letra e conhecer a interpretação da doutrina e a aplicação da jurisprudência" (CONSTANTINESCO, 1998, p. 136).

Nesta época, contribuíram para o desenvolvimento do direito comparado autores como von Stein, que trouxe a "primeira tentativa de expor de forma sistemática e comparativa a ciência e o Direito administrativo dos principais países europeus"; Robert Mohl; Otto Mayer; Unger; Ernest Glasson; von Liszt, que foi o promotor da comparação no direito penal; Seleilles; entre outros (CONSTANTINESCO, 1998, p. 137-142). 
Aqui no Brasil, pode-se citar a contribuição de Clóvis Bevilaqua, autor do nosso Código Civil de 1917 e professor de legislação comparada na Faculdade de Recife, que, em 1893, publica sua primeira obra, trazendo estudos sobre os problemas do direito comparado. Ademais, a sua obra Código Civil dos Estados Unidos do Brasil é um grande exemplo da utilização do método comparatista para interpretação do novo Código Civil (RODRIGUES JUNIOR, 2014, p. 3).

Acerca da produção em Direito comparado no Brasil, Orione Dantas Medeiros (2010, p. 18) menciona:

Os primeiros trabalhos datam do final do século XIX, na Faculdade de Direito do Recife, com os escritos de Tobias Barreto, no contraponto feito entre teoria jurídica brasileira e teoria alemã, e os estudos sistemáticos de Clóvis Beviláqua (LOSANO, 2007, p. 15-40), retratados na "Aplicação do methodo comparativo ao estudo do direito", de 1891, e o "Resumo das Lições de Legislação Comparada sobre o Direito Privado", de 1897. No início do século XX, Cândido Luiz Maria de Oliveira publica o "Curso de Legislação Comparada".

Posteriormente, firmando-se a vertente comparatista do século, é fundada na França a primeira Sociedade de Legislação Comparada, em 1869, constituída a fim de facilitar a solução dos conflitos de leis, o que dá ensejo à criação de outras instituições análogas. Conforme Leme (1960, p. 59):

A esta, outras notáveis instituições se juntaram, recolhendo documentação, ou favorecendo os estudos do Direito Comparado. Assim na Alemanha a Associação Internacional de Direito e Economia Política Comparados, (Internationale Vereinigung für vergleichende Rechtswissenschaft und Volkswirtschaftslehre), fundada em Berlim em 1894, pelo juiz Felix Meyer; na Itália, o Instituto de Direito Comercial Comparado, da Universidade Bocconi, de Milão e o Instituto de Estudos Legislativos, de Roma; na Bélgica, o Instituto Belga de Direito Comparado; na França, o Instituto de Direito Comparado, de Lyon; no Brasil, a Sociedade de Direito Comparado, do Rio dê Janeiro.

Além disso, houve a utilização do método comparativo para a criação dos códigos nacionais, a chamada onda de codificações a nível mundial. Segundo Constantinesco (1998, p. 185):

A difusão dos novos códigos e, especialmente, daqueles franceses no mundo, coincide durante a segunda metade do século com um fenômeno de repercussão mundial: de uma parte, o acesso de numerosos "povos sem história" à independência política; de outra, os propósitos de modernização de algumas nações com uma existência histórica reconhecida, mas circunscrita a formas de vida velhas e inadequadas. Entre os primeiros encontram-se os países da Europa Central e Oriental e os da América latina. Aqueles povos, do tcheco ao grego, do romeno ao sérvio, descobrem, com a 
consciência nacional, a identidade e a sua existência histórica, ocultada sob a pressão dos impérios estrangeiros que dominam esta parte do continente: os impérios russo, austríaco e turco. Já a partir do final do século XVIII, tchecos, romenos, eslovenos, croatas, sérvios etc., começam a lutar contra os impérios que os dominam. Um fenômeno paralelo se verifica ao mesmo tempo na América Latina, onde os povos se libertam progressivamente da dominação ibérica.

Destarte, ao final do século XIX, como bem salienta Rodriguez Junior (2014, p. 3), o comparatismo era mais do que um berloque ou um símbolo de erudição, era uma necessidade.

\subsection{Terceiro Período (1900 - 1950)}

Esse período, segundo Constantinesco (1998, p. 206), constitui uma tomada de consciência da importância do direito comparado, dando início à discussão no plano internacional.

Considera-se que o marco do terceiro período foi o Congresso de Paris, realizado em 1900, sendo a data inicial da fase moderna comparatista. Nesse congresso, foram debatidos temas de direito público, tendo as discussões sido registradas "nos respectivos 'Procèsverbaux' como o do prof. LERNANDE, 'Legislation Comparée et Droit Public' e de M. DESLANDRES, neste mesmo sentido geral, 'Observations sur la fonction de la Science de droit comparé par rapport au droit public' (PEREIRA, 1955, p. 46).

Conforme leciona Pereira (1955, p. 36):

Pode-se fixar o Congresso de Paris, realizado em 1900, como o momento em que se desenhou o rumo novo que o comparatismo tomou no mundo, pois é certo que não é de hoje nem de ontem a tendência do jurista, no sentido de realizar o confronto de seu direito nacional com o direito extrangeiro. Costuma-se apontar frequentemente a "Política" de ARISTÓTELES como dos primeiros ensaios do gênero no mundo, resultante da história comparada do direito público, como também o jus gentium é considerado uma elaboração comparatista do direito dos povos da bacia mediterrânea. Mas êsses primeiros exemplos, observa o prof. SOLA CANIZARES, não representam "una obra reflexiva y científica a base de um processo de comparaciòn".

Foi em 1900 que fora confiada a Edouard Lambert, um dos mais importantes autores desse período, a cátedra de História Geral do Direito, na Faculdade de Direito de Lyon. Nesse ínterim, o teórico apresentou no Congresso de Paris o trabalho intitulado "Concéption générale, définition, méthode et histoire du Droit Compare" (LEME, 1960, p. 63). 
Ademais, no Congresso, o problema de saber se o direito comparado é um método ou uma ciência autônoma foi colocado de maneira clara, tendo Lambert ocupado-se dessa questão (CONSTANTINESCO, 1998, p. 207).

Além da questão supracitada, segundo René David (2002, p. 27), diversos problemas foram colocados nas pautas de discussão durante o Congresso de Paris:

\begin{abstract}
Interrogaram-se sobre se o direito comparado devia ser considerado como um ramo autônomo da ciência do direito ou, se pelo contrário, ele não passava de um simples método, o método comparativo, aplicado à ciência jurídica; esforçaram-se por assinalar ao direito comparado um domínio próprio, distinguindo-o da história comparativa do direito, da teoria geral do direito e da sociologia jurídica; procurou-se determinar em que ramos do direito se podiam retirar vantagens de estudo comparativo; pôs-se a questão de saber que direitos era útil, oportuno ou mesmo permitido comparar entre si; chamou-se a atenção para os perigos que os juristas deviam evitar, quando se empenhassem nos estudos de direito comparado.
\end{abstract}

Dessa forma, o Congresso trouxe muitas contribuições para o desenvolvimento do direito comparado, entretanto, não solucionou os problemas principais, tendo em vista que muitas questões foram tratadas de forma ambígua por seus redatores, perdurando, principalmente, a divergência acerca do caráter científico ou metodológico.

Outro autor de suma importância, sendo um dos organizadores do Congresso, foi Saleilles, que conduziu à concepção de que o direito comparado poderia ser usado como meio de política legislativa e jurisprudencial (CONSTANTINESCO, 1998, p. 209).

Nesse toar, podemos destacar como grandes nomes dessa época Ernst Rabel, um dos responsáveis pela reabertura da Alemanha à cooperação acadêmico-jurídica no primeiro pósguerra, deixando como herança o desenvolvimento do método comparativo funcional; Pierre Arminjon, Barão Boris Nolde e Martin Wolff, que também ocuparam uma posição de enorme relevo no direito comparado, graças a seu monumental Traité de Droit Comparé, editado pela francesa LGDJ, em Paris, no ano de 1950 (RODRIGUES JUNIOR, 2014, p. 1-2).

Importante mencionar que René David, foi um dos principais autores do século XX, com a obra Os Grandes Sistemas do Direito Contemporâneo, na qual dedicou-se ao estudo comparatista da evolução histórica do Direito, por meio da reunião de vários direitos estrangeiros, classificados por ele como "família de direito".

Contudo, apesar do desenvolvimento, após a Primeira Guerra Mundial, ocorre o fracasso da etnologia jurídica e a consolidação do materialismo e do positivismo. Segundo Constantinesco (1998, p. 232), “a vontade de integrar a comparação em um conjunto de ideias 
e de interpretar os seus resultados em um quadro que supere o estreito positivismo jurídico é abandonada depois de Kohler".

Dessa forma, tem-se uma situação verdadeiramente catastrófica, tendo em vista que o direito comparado passa a ser confundido mais uma vez com o direito estrangeiro, o que fez com que a questão prática perdesse força, bem como a discussão acerca da questão do Direito comparado como método ou ciência.

Contudo, após a Segunda Guerra Mundial, a situação passa a se reverter, de forma que o interesse pelo direito comparado começa a renascer muito lentamente, recebendo novos impulsos, com a realização de diversas conferências e eventos análogos para a discussão de problemas e institutos jurídicos em comum. Para Constantinesco (1998, p. 245) “esse período se caracteriza por uma nova tomada de consciência da importância do Direito comparado, que se estende além do âmbito dos países europeus".

\title{
3 NATUREZA DO DIREITO COMPARADO: CIÊNCIA OU MÉTODO?
}

Conforme já mencionado, a questão acerca da natureza do direito comparado é objeto de diversas discussões entre os estudiosos do assunto, desde o início da sua evolução até hoje. Desse modo, ainda coexistem certezas e incertezas, de forma que não há uma posição pacífica entre os autores sobre tal questão.

Nesse ínterim, a divergência tornou-se objeto de grande interesse após o Congresso de Paris, em 1900. Entretanto, consoante Ernesto Leme (1960, p. 39), apesar de o evento ter ensejado diversas discussões, não se encontrou uma uniformidade acerca da conceituação do direito comparado, separando-se os juristas em sua conceituação. Para o autor:

\begin{abstract}
Ainda está em aberto a questão de sua existência autônoma, a saber se é um ramo novo da ciência jurídica ou se não passa de aplicação do método comparativo ao estudo do direito, da mesma forma que já de há muito se fazia com as ciências exatas ou as ciências abstratas, uma vez que as classificações das espécies em zoologia e botânica, como a classificação genealógica ds línguas, ou as classificações ethnográficas são meras aplicações do método comparativo.
\end{abstract}

Segundo Constantinesco (1998, p. 280), sobre o assunto, existem três correntes. A primeira esclarece que a disputa tem meramente um interesse acadêmico. A segunda corrente dispõe que o direito comparado é apenas um método. A terceira, e última orientação, afirma que o direito comparado é somente ou "também" uma ciência autônoma.

A respeito da primeira corrente, Flavia Pessoa $(2009,35)$ aduz que: 
Os autores que perfilham a primeira corrente vêem no Direito comparado um método do qual apreciam os resultados e consideram supérfluas todas as outras discussões ou ainda pensam encontrar a solução em modificações de caráter terminológico. A argumentação usada com mais frequiência é aquela que considera a controvérsia sobre a natureza do Direito comparado teórica e estéril, porque sem importância prática.

No que diz respeito à segunda corrente, os autores sustentam a tese de que o direito comparado é somente um método, sendo esta a corrente dominante. Dessa forma, defendem essa orientação autores como Kaden, De Francisci, René David, Lambert e Lino de Moraes Leme.

Nesse contexto, René David argumenta que o direito comparado não pode constituir ciência autônoma por não constituir um corpo de regras, tal qual os demais ramos do direito. Ademais, "o Direito comparado não é uma parte do Direito positivo de uma nação qualquer, como os Direitos civil e administrativo" (RENÉ DAVID, Traité, 3 apud CONSTANTINESCO, 1998, p. 290).

Orione Dantas de Medeiros (2010, p. 316-317) esclarece que:

Quando se afirma a não existência do Direito Comparado como ciência jurídica autônoma, geralmente toma-se como ponto de partida uma sistemática do Direito, na qual se fala de Direito Civil, de Direito Penal ou de Direito Administrativo. Nesse sentido, considera-se que o Direito Comparado não tem um objeto próprio, como o têm os diferentes ramos do direito. Adotando tal visão, é que diversos autores apontam a impossibilidade de autonomia do Direito Comparado como um ramo da ciência jurídica.

Para os que adotam tal perspectiva, o Direito Comparado é método jurídico de comparação que se aplica às matérias que pertencem a um outro ramo do Direito, ou melhor, um modo científico de unificação (coordenação) e aperfeiçoamento dos institutos jurídicos vigentes.

Outro defensor dessa corrente foi Gutteridge, que, em 1946, na obra Comparative Law, afirmou que que o direito comparado consiste no emprego do método comparativo, e não um ramo da ciência, de forma que "o estatuto científico do direito comparado é colocado em xeque de forma inédita até então" (KHALED JR., 2011, p. 4).

No que diz respeito à terceira corrente, muitos estudiosos do direito comparado procuraram solidificar a sua classificação como ciência autônoma, ou seja, de um complexo de conhecimentos independente e particular. Entre os defensores dessa vertente, destaca-se Marc Ancel, com a obra intitulada Utilidade e métodos do direito comparado, de 1971.

Nesse toar, aqui no Brasil, defendeu a corrente o autor Caio Mario da Silva Pereira, que afirma que o direito comparado possui o caráter de ciência autônoma "por não limitar sua 


\section{A PESQUISA E O DIREITO COMPARADO: UM PANORAMA EVOLUTIVO E OS DESAFIOS ENFRENTADOS NO BRASIL}

atuação apenas à comparação de direitos, mas, procurar, através da comparação, a obtenção de resultados, de finalidades, e de objetivos que lhe são próprios” (PEREIRA, 1955, p. 6).

Entretanto, embora tenha tido grandes defensores, os argumentos apresentados até hoje na defesa de que seria uma ciência parecem insatisfatórios, perdendo força ao longo do tempo. Para Constantinesco (1998, p. 321) "a vontade de construir a ciência autônoma dos direitos comparados é clara; as tentativas são múltiplas, os resultados decepcionantes”.

Destarte, embora haja diversas opiniões acerca do tema, não há uma uniformidade no ordenamento, de forma que tal questão continua em aberto, sendo, ainda, objeto de numerosos debates. Segundo Serrano (2006, p. 5) o problema permanece sendo um desafio para os estudiosos desse ramo, porquanto, mesmo após décadas de desenvolvimento, não foi adotada, de maneira uniforme, uma tese finalizada acerca do direito comparado.

Contudo, importa ressaltar que, apesar de importante, tal discussão não é de extrema necessidade, a ponto de o uso do direito comparado ser obstado por conta dela. Nesse sentido, Rodolfo Sacco (2001, p. 33-34), na obra Introdução ao Direito Comparado, leciona:

Em cada caso, cada disciplina é em parte ciência, em parte método. Em sentido mais estrito, pode-se entender como método um conjunto de procedimentos pré-escolhidos para chegar a certos resultados (e dever-se-ia então entender por ciência em sentido estrito um particular campo de indagação, ou então um certo domínio de dados). Isto posto, pode-se ver como não existe um único modo de comparar: é reciprocamente possível utilizar métodos diversos (estruturalismo, funcionalismo etc.) na comparação; e pode-se ver também como existe efetivamente um âmbito particular de fenômenos dos quais se ocupa a comparação a respeito de outras disciplinas jurídicas - a circulação de modelos; as suas dissociações e relações internas; as homologações e a correspondentes comparações. Quem diz que a comparação é método, tem uma visão limitada do método da comparação (porque não observa que se podem usar mais métodos para comparar, e que não existem o método puro de comparar), quando não tem uma visão limitada dos seus escopos e do seu objeto (porque não observa, ou não conhece, o seu específico, e já desenvolvido, campo de indagação).

Ou seja, para que o direito comparado atinja a sua finalidade, seja como instrumento para a resolução de problemas práticos ou no ativismo legislativo, não é preciso que este, necessariamente, enquadre-se em um conceito. 


\title{
4 OS DESAFIOS DA PESQUISA COM O DIREITO COMPARADO NO BRASIL
}

Posto que já fora traçado todo o processo evolutivo por onde se desenvolveu a comparação jurídica, bem como a controvérsia existente acerca da sua natureza, trataremos nesse tópico sobre a discussão contemporânea no que diz respeito aos desafios enfrentados no âmbito do direito comparado, no Brasil.

Incialmente, faz-se necessário salientar que o estudo do direito comparado é de suma importância, haja vista que, a cada dia, as relações entre os países têm se intensificado, em virtude da globalização, de forma que tal estudo nos leva a uma melhor compreensão da realidade dos sistemas jurídicos e a um aperfeiçoamento do direito nacional, por servir de direcionamento ao legislador nacional.

Contudo, apesar de ser essencial, a pesquisa no âmbito jurídico, no Brasil, enfrenta diversas dificuldades, de forma que, no que diz respeito ao direito comparado, os desafios são ainda maiores.

Nesse ínterim, tais dificuldades, no geral, se dão porquanto exista um atraso do direito enquanto disciplina acadêmica, não tendo esta conseguido acompanhar o crescimento qualitativo da pesquisa científica em ciência humanas no Brasil, nos últimos trinta anos, conforme menciona Marcos Nobre (2004, p. 2). Para o autor, "esse relativo atraso se deveu, sobretudo, a uma combinação de dois fatores fundamentais: o isolamento em relação a outras disciplinas das ciências humanas e uma peculiar confusão entre prática profissional e pesquisa acadêmica" (NOBRE, 2004, p. 4).

Outra dificuldade enfrentada diz respeito à falta de preparação dos pesquisadores para praticá-lo, de modo que existe uma grande confusão entre o direito comparado e o direito estrangeiro. Acerca do tema, Flávia Pessoa (2008, p. 4) leciona:

\begin{abstract}
A distinção entre o direito comparado e o direito estrangeiro é que o direito comparado vai além do estudo e da descrição das leis estrangeiras. Um estudo sério de direito estrangeiro, o mais completo quanto possível, é indispensável antes de toda comparação propriamente dita. O fato é que devem ser evitadas aproximações levadas a efeito por abordagens horizontais, sem estudo vertical suficiente. Assim é que Ancel (1980, p. 105) aponta que o direito comparado está na dependência dos estudos de direito estrangeiro e que o direito estrangeiro é a matéria-prima do direito comparado.
\end{abstract}

Orione Dantas Medeiros (2010, p. 3) aduz que:

(...) para o estudo de Direito Comparado, não basta fazer comparação entre a legislação nacional e a legislação estrangeira (elementos do Direito Comparado); é preciso uma análise dentro de um quadro geral em que se 
incluem aspectos doutrinários e jurisprudenciais. O Direito Comparado tem a comparação (semelhanças ou diferenças), entre sistemas e/ou institutos jurídicos vigentes, como seu objeto. Os grandes sistemas jurídicos e as famílias de direito (as diferenças e semelhanças) não são opostos, mas conceitos interdependentes que estão necessariamente em tensões.

Dessa forma, são raros os títulos que trazem uma efetiva comparação entre os direitos, reconhecendo as semelhanças e diferenças com base em variáveis definidas previamente, sendo diversos trabalhos apenas uma justaposição entre os direitos nacionais e estrangeiros.

Nesse toar, denota-se que a falta de preparação dos juristas no âmbito do direito comparado decorre, principalmente, do fato não se ter nas instituições o ensino a matéria como se faz necessário para que se forme pesquisadores qualificados, haja vista que, para uma correta comparação, é imprescindível uma base sólida de conhecimento. Ou seja, há uma escassez de docentes e cursos qualificados para tanto. Destarte, para Paula Cury (2014, p. 178):

No Brasil, apesar de proliferarem projetos de pesquisa, de graduação e pósgraduação, em que é feita alusão ao objetivo de comparar ordenamentos, faltam - até mesmo pela atribuição de um papel secundário à disciplina jurídica do Direito Comparado no currículo de grande parte dos cursos de Direito do país - conhecimentos elementares sobre conceitos e métodos de Direito Comparado que permitam a obtenção de resultados efetivos, capazes de trazer à luz as possibilidades reais, e não meramente colorandi causa, de contribuição dessa ciência para a solução de problemas jurídicos.

Segundo Vera Jocob de Fradera (in SACO, 2001, p. 6):

Hoje, no Brasil, as faculdades de Direito que incluem em seus curricula a disciplina Direito Comparado, nos Cursos de Mestrado ou Doutorado, estudam, em verdade, Legislação Comparada, de vez que não praticam o autêntico comparatismo, que consiste, como vimos, na busca das razões das semelhanças ou das diferenças entre normas, institutos e sistemas jurídicos, objeto da comparação.

Ou seja, o ensino do direito comparado, em nível de graduação, tendo como objeto o exame comparativo dos grandes sistemas jurídicos contemporâneos, abrangendo tanto o direito privado quanto o direito público, ainda é raro em nosso país. Ana Lucia de Lyra Tavares (2006, p. 74) menciona uma solução para o problema:

De nossa parte, consideramos que seria desejável que os cursos de direito comparado sob esta acepção ampla fossem mais frequentemente implementados no Brasil. O ensino por ramo do direito é extremamente importante, mas é o direito comparado em geral que melhor permite de alcançarem-se os objetivos de aprofundamento dos conhecimentos dos 
sistemas jurídicos estrangeiros, de aprimoramento do direito nacional e de aproximação dos povos pelo respeito de suas identidades culturais.

É possível elencar também como desafio a dificuldade linguística, ou seja, a dificuldade a respeito da língua utilizada pelo ordenamento do país objeto da comparação. Ademais, atrelado a esse fato está a escassez de materiais sobre o tema. Dessa forma, têm-se traduções em um número limitado, além de uma qualidade que deixa bastante a desejar, reduzindo-se, assim, o campo de pesquisa. Entretanto, “esse ponto pode ser solucionado com a preparação metodológica e intelectual que englobará a adequada terminologia utilizada pelo sistema ou ordenamento jurídico estrangeiro e seu significado”. (MEDEIROS, 2010, p. 318).

Com efeito, para realizar um trabalho envolvendo o direito comparado, é preciso que se tenha conhecimentos profundos de Sociologia, História, Antropologia, Política e Linguística, pois faz-se necessário entender a configuração do sistema jurídico estrangeiro como um todo, no que diz respeito à sua origem, cultura, bem como como se deu sua evolução e o por quê da aplicação dos dispositivos.

Nesse sentido, Marc Ancel (1980, p. 17-18), considerando que, apesar de existirem várias legislações, há uma universalidade do direito, aponta que o estudo comparado permite que se conheça melhor o próprio direito nacional. Segundo o autor:

No terreno prático e concreto, ao inverso, é por demais evidente que o conhecimento do direito estrangeiro - ao menos o contato com o direito do estrangeiro - é frequentemente indispensável ao advogado, ao juiz e ao árbitro (notadamente em matéria de arbitragem comercial internacional), ao homem de negócios, ao negociador, ao diplomata. Todos os sistemas de conflitos de leis admitem, em certos casos, a aplicação da lei estrangeira: é preciso ignorá-la? Como, de resto, poderíamos fazê-lo, se este mesmo sistema de conflito de leis nos obriga a confrontar esta lei estrangeira com a nossa ordem pública nacional?

Dessa maneira, devemos reconhecer que o direito comparado pode contribuir, não só para o legislador, mas para o profissional do direito no geral, sendo necessária a mudança em relação à postura que os estudante têm diante da pesquisa com o direito comparado. Acerca da questão, dispõe Caio Mario da Silva Pereira (1955, p. 42):

Impressionado com o fato de serem pouco freqüentadas as classes de direito comparado, o prof. RUDOLF B. SCHLESINGER observa que os estudantes na maioria dos países continuarão a se desinteressar pelo direito comparado a não ser que se conduza o seu ensino no sentido de contribuir para a sua formação profissional, seja como advogado ou juiz, seja como legislador ou administrador. Mas é preciso, mesmo cumprindo sua finalidade prática, evitar considerá-lo (e o aconselha ASCARELLI) um simples catálogo de artigos de legislação estrangeira que o reduziria a mera resenha estatística. 
Nesse ínterim, para que grande parte dos desafios fossem resolvidos, "o ideal seria a criação, nas Universidades, de institutos de direito comparado, independentes daqueles de direito internacional, mas em articulação com os mesmos” (TAVARES, 2006, p. 85).

O estudo do Direito Comparado é de extrema importância e necessidade, visto que nos permite alcançar melhor os diferentes ordenamentos jurídicos; analisando o que há em comum entre os dispositivos, bem como suas diferenças, fazendo com o nosso próprio ordenamento seja mais bem compreendido.

\section{CONSIDERAÇÕES FINAIS}

Percebemos que o direito comparado passou por um lento processo evolutivo para chegar aos dias atuais, desde o seu crescimento embrionário na antiguidade, passando pela sua origem oficial no século XIX, até o seu desenvolvimento, de fato, ao longo do século XX.

Nesse toar, surgiram diversas questões acerca do direito comparado, sendo a divergência "ciência ou método" objeto de muitas discussões entre os pesquisadores. Tais discrepâncias acarretaram em dificuldades no desenvolvimento deste, e, na contemporaneidade, os desafios ainda permanecem aqui no Brasil.

Entre os obstáculos podemos elencar as poucas traduções, algumas com qualidade discutível; a confusão entre estudos de Direito Estrangeiro e de Direito Comparado; a dificuldade linguística; além do despreparo, tanto por parte dos docentes, quanto dos discentes e das instituições.

Contudo, faz-se necessário que essas dificuldades sejam rompidas e que haja uma mudança de postura, tendo em vista que o estudo do direito comparado é suma importância para nos levar a uma melhor compreensão da realidade dos sistemas jurídicos, indo além do aspecto legislativo, proporcionando um maior conhecimento do próprio sistema jurídico nacional, além de promover uma consciência integradora entre os ordenamentos, permitindo buscar soluções para problemas globais.

\section{REFERÊNCIAS}

ANCEL, Marc. Utilidade e Métodos do Direito Comparado. Porto Alegre: Sérgio Antonio Fabris Editor, 1980.

ASCENSÃO, José de Oliveira. Sistemas atuais de direito. Revista da Faculdade de Direito da UFMG, n. 17, p. 7-32, 1976. 
CONSTANTINESCO, Leotin-Jean. Tratado de direito comparado. Tradução: Maria Cristina de Cicco. Rio de Janeiro: Renovar, 1998.

CURY, Paula Maria Nasser. Métodos de Direito Comparado: desenvolvimento ao longo do século XX e perspectivas contemporâneas. Revista de Estudos Constitucionais, Hermenêutica e Teoria do Direito - RECHTD, v.6, n.2, jul-set 2014. p.176-185. DANTAS, Ivo. Direito comparado como ciência. Revista de Informação Legislativa, Brasília a. 34 n. 134 abr./jun. 1997.

DAVID, René. Grandes Sistemas Jurídicos Contemporâneos. São Paulo: Martins Fontes, 2002.

KHALED JR., Salah H. Trajetória histórica e questões metodológicas de direito comparado. Âmbito Jurídico, Rio Grande do Sul, $\mathrm{n}^{\circ}$ 74, $1^{\circ}$ mar. 2010. Disponível em: $<\mathrm{http}: / / \mathrm{www}$. ambitojuridico.com.br/site/index.php?n_link=revista_artigos_leitura\&artigo_id= 7267>. Acesso em 27 jun. 2017.

LAKATOS, Eva Maria; MARCONI, Marina de Andrade. Metodologia científica. 4.ed. São Paulo: Atlas, 2004.

LEME, Ernesto. Direito Civil comparado. Revista da Faculdade de Direito de São Paulo, v. 55,1960 .

MEDEIROS, Orione Dantas de. Direito Constitucional Comparado: Breves aspectos epistemológicos. Revista de Informação Legislativa. Brasília, a. 47, n. 188, out./dez. 2010.

NOBRE, Marcos. Apontamentos sobre a pesquisa em Direito no Brasil. Cadernos Direito GV, n. ${ }^{\circ}$ 1, São Paulo: Fundação Getúlio Vargas, set./2004.

PESSOA, Flávia Moreira Guimarães. Manual de metodologia do trabalho científico: como fazer uma pesquisa de direito comparado. Aracaju: Evocati, 2009.

PEREIRA, Caio Mário da Silva. Direito Comparado e seu estudo. Revista da Faculdade de Direito de Minas Gerais, 1955.

REBOUCAS, Gabriela Maia; LEITE, Martha Franco; MARQUES, Verônica Teixeira. Pesquisa comparativa em ciências sociais e humanas: um panorama de seus usos. Interfaces Científicas-Humanas e Sociais, v. 5, n. 2, p. 21-32, 2016.

RODRIGUES Jr., Otávio Luiz. Desenvolvimento do Direito Comparado nos séculos XIX e XX. Revista Consultor Jurídico, 5 mar. 2014. Disponível em:

$<$ http://www.conjur.com.br/2014-mar-05/direito-comparado-desenvolvimento-direitocomparado-seculos-xix-xx>. Acesso em 25 jun. 2017.

RODRIGUES Jr., Otávio Luiz. O Direito Comparado nos séculos XIX e XX (parte 2). Revista Consultor Jurídico, 12 mar. 2014. Disponível em: < http://www.conjur.com.br/2014mar-12/direito-comparado-desenvolvimento-direito-comparado-seculos-xix-xx >. Acesso em 25 jun. 2017. 
SACCO, Rodolfo. Introdução ao direito comparado. Tradução de Vera Jacob de Fradera. São Paulo: RT, 2001.

SERRANO, Pablo JIMENEZ. Como Utilizar o Direito Comparado para a Elaboração de Tese Científica. Rio de Janeiro: Forense, 2006.

SCHNEIDER, Sergio; SCHIMITT, Cláudia Job. O uso do método comparativo nas Ciências Sociais. Cadernos de Sociologia, Porto Alegre, v. 9, p. 49-87, 1998.

TAVARES, Ana Lúcia Lyra. O ensino do direito comparado no Brasil contemporâneo. Revista Direito, Estado e Sociedade, v. 9, n. 29, 2014.

VARELLA, Marcelo Dias; ROESLER, Claudia Rosane. Dificuldades de avaliação de publicações na área de Direito. Revista Brasileira de Pós-Graduação, v. 9, n. 18, 2012. 